\title{
Using Factorial Design Methodology to Assess PLA-g-Ma and Henequen Microfibrillated Cellulose Content on the Mechanical Properties of Poly(lactic acid) Composites
}

\author{
M. Dzul-Cervantes, ${ }^{1}$ P. J. Herrera-Franco, ${ }^{1}$ T. Tábi, ${ }^{2,3}$ and A. Valadez-Gonzalez ${ }^{1}$ \\ ${ }^{1}$ Centro de Investigación Científica de Yucatán, A.C. (CICY), Unidad de Materiales, Calle 43 \# 130, Col. Chuburná de Hidalgo, \\ 97200 Mérida, YUC, Mexico \\ ${ }^{2}$ MTA-BME Research Group for Composite Science and Technology, Muegyetem rkp. 3, Budapest 1111, Hungary \\ ${ }^{3}$ Department of Polymer Engineering, Faculty of Mechanical Engineering, Budapest University of Technology and Economics, \\ Muegyetem rkp. 3, Budapest 1111, Hungary \\ Correspondence should be addressed to A. Valadez-Gonzalez; avaladez60@gmail.com
}

Received 8 January 2017; Accepted 26 March 2017; Published 30 April 2017

Academic Editor: Antje Potthast

Copyright (C) 2017 M. Dzul-Cervantes et al. This is an open access article distributed under the Creative Commons Attribution License, which permits unrestricted use, distribution, and reproduction in any medium, provided the original work is properly cited.

\begin{abstract}
In this work, a $2^{2}$ factorial design was used to study the effect of microfibrillated henequen cellulose fibers (HENCEL) and PLA-gMA coupling agent contents on the tensile, flexural, and impact mechanical properties and the heat deflection temperature (HDT) of biodegradable PLA composites. The results show that the principal effects of HENCEL and MA are statistically significant for the tensile, flexural, HDT, and impact strength properties of PLA composites. Regarding the interactions between the principle effects, MA-HENCEL, there are differences with respect to the mechanical property; for example, for tensile and flexural mechanical properties, there is a synergistic effect between MA and HENCEL, whereas for HDT and impact strength there is not any. The micromechanical analysis shows an excellent agreement between the measured and the estimated values for both the composite tensile strength and the elastic modulus and only slight deviations were noticed for high microfibrillated cellulose fibers content. The morphological analysis via SEM indicated that the addition of PLA-g-MA improved the fiber-matrix adhesion because of the HENCEL unbounding and pull-out decreases from the PLA matrix. The use of appropriate values of matrix strength and stiffness and considering the improved fiber-matrix adhesion of the coupling agent yield a good agreement between experimental and estimated values.
\end{abstract}

\section{Introduction}

Nowadays, most polymeric materials are made from monomers derived from petroleum; however, this is a nonrenewable resource. On the other hand, the disposal of items derived from petroleum, such as fast food utensils, containers for packaging, and garbage bags, has created major environmental problems $[1,2]$. To solve these problems, the recycling of materials made from petroleum and the development of new materials with more friendly features to the environment are an attractive alternative, such as being biodegradable and, ideally, made from renewable sources [3].

The interest in the use of biopolymers as an alternative for the replacement of the polymers derived from oil has increased in recent years, mainly due to problems such as environmental concerns and global warming $[1,3-6]$. Furthermore, most thermoplastic polymers can be recycled; however, only a small amount of them is recycled, so biopolymers have become an important replacement of some of the plastics because their "life cycle" is shorter than that of the former before their complete degradation; that is why biodegradable plastics have increasingly attracted the attention of both researchers and industrial executives. Also, in order to be competitive with the petroleum derived polymers, biopolymers need to have acceptable prices and to be processed using similar methods to those used for the processing of synthetic plastics $[7,8]$. 
Poly(lactic acid) (PLA) is a bioplastic, which is suitable for applications requiring short "useful life times" such as packaging trays, food containers, and cutlery $[4,5,9,10]$. Therefore, there exist several possible applications for PLA; however, its use is limited due to its relatively high price, its brittleness, and low barrier properties in food packaging items and difficulties in its processing. To increase the mechanical properties of PLA, it has been reinforced using fibers [9-12]; for example, cellulose suspensions have been fed directly to the polymer melt using an extruder [13].

Biocomposites are materials made from a bioplastic matrix and a reinforcing material (usually natural fibers), which are "friendly" to the environment and biodegradable. These biocomposites have been developed rapidly, mainly due to the improvements in the processes of transformation and the reduction of production costs of bioplastics. Recent studies have reported filled cellulosic-biocomposites and bioplastics with improved mechanical properties [9, 14-17]. For example, PLA biocomposites reinforced with natural fibers are one of the many areas that have been discussed by researchers in materials science in recent years. However, there exist some issues such as poor interfacial interaction between the matrix and the natural fiber [18-21] as well as difficulties in their processing $[14,19,22,23]$, and there are still several challenges to overcome.

Today, the majority of polymers are used for packaging products, automobiles, space, food industry, and so forth $[22,24,25]$. Composites containing cellulose fibers as reinforcement of epoxy or formaldehyde resins, polypropylene, polymethyl methacrylate, polystyrene, and styrene copolymers have been extensively studied in recent years $[15,16$, 22]. However, after use, the disposal of waste of composite materials, usually made of epoxy resin or unsaturated polyester reinforced with glass fibers, carbon, or aramid, has increased consumer awareness about the possible environmental impact of nonbiodegradable polymers [22, 26], and these materials are considered as critical [22].

Cellulose is the most abundant natural biopolymer on earth, which is renewable, biodegradable, and nontoxic [7, $16,27,28]$. It is a natural polymer composed of units of $\beta$-D-glucopyranose, which contains three hydroxyl groups per anhydroglucose unit (AGU). The chemical structure of cellulose contains three hydroxyl groups $(\mathrm{OH})$, two of which form hydrogen bonds within the cellulose macromolecules (intramolecular), while the other groups form hydrogen bonds with other cellulose molecules (intermolecular) [28]. These $\mathrm{OH}$ groups contained in the structure of the cellulose molecule provide a high degree of glucose functionality [29]. Knowledge of the molecular structure of cellulose is vital to explain the characteristic features of cellulose, such as hydrophilicity, chirality, biodegradation, and high functionality. As a renewable material, cellulose and its derivatives have been widely studied, focusing on its biological, chemical, and mechanical properties. The cellulose fibers can be obtained by mechanical and semichemical mechanical processes. Among the mechanical processes the following may be mentioned: refining processes or high shear homogenization and sonication. As for the chemical processes, pulping processes can be reported [30], which consist of an enzymatic hydrolysis with cellulase or acid hydrolysis or hydrochloric or sulfuric acid.

Maleic anhydride (MA) is a carbonyl compound, $\alpha$-, $\beta$-unsaturated, containing one carbon-carbon double bond $(\mathrm{C}=\mathrm{C})$ and two carboxylate groups. This structural combination greatly increases the grafting reaction of heterocyclic ring with the polymeric matrix in the presence of an radical initiator, resulting in cross-linking or strong adhesion at the interface. MA is usually used to modify the polymer matrix by grafted copolymerization. The copolymers formed are known as coupling agents [31]. The MA is one of the most reactive compatibilizers used because of its good chemical reactivity, low toxicity, and low potential for cross-linking under conditions of free radical grafting [32]. The MA can functionalize polymers containing hydroxyl functional groups at their ends [11]. The mechanism of compatibilization of the maleic anhydride is based on the fact that maleic anhydride improves the intermolecular force forming hydrogen bonds between the grafted maleic anhydride and the polymer backbone. [33]. MA has been used to improve the compatibility between the PLA and starch as reported in several research projects $[34,35]$, resulting in an increase of hardness and ductility of PLA-starch blends. Various studies of PLA reinforced with natural fiber have been reported where a variety of natural fibers were investigated in detail [4, 21, 24-30, 36, 37]; however, the use of henequen (Agave fourcroydes) microfibrillated cellulose as reinforcing material in PLA has not yet been explored. Therefore, the factorial design methodology, that is, a two-level full factorial design $2^{2}$ with two central points, was employed to investigate the effect of microfibrillated henequen cellulose (HENCEL) and PLA-g-MA (MA) coupling agent contents on the tensile, flexural, impact, and the heat deflection temperature (HDT) mechanical properties of biodegradable PLA composites.

\section{Materials and Methods}

2.1. Materials. Semicrystalline PLA injection moulding grade resin (type Ingeo 3251D from NatureWorks Ltd., USA, with a D-lactide content of $4 \%$ ) was used as thermoplastic matrix. Henequen fibers provided by DESFIYUSA Co. (Desfibradora Yucateca, S.A.) were used as source for the microfibrillated cellulose. Maleic anhydride and benzoyl peroxide from Aldrich were used for the preparation of the PLA-g-MA coupling agent.

2.2. Microfibrillated Cellulose (HENCEL) from Henequen Fibers. The procedure to obtain the cellulose from the henequen fibers consists of (1) acid hydrolysis, (2) chlorination, (3) alkaline extraction, and (4) bleaching. The details have been reported elsewhere [38]. Next, the cellulose fibers were treated in a "scrubber diaphragm" in which a slotted sieve of $0.15 \mathrm{~mm}$ was used to separate the CF of different sizes. Subsequently, the CF were centrifuged in a Bluepoint centrifuge, model "scbp1500," to remove excess water and finally homogenized in a blender (from Krups, model 418 PowerMix) and they were fibrillated using a "Dutch stack" 
equipment for a period of 115 minutes. Finally the microfibrillated cellulose fibers were dried at $105^{\circ} \mathrm{C}$ during $24 \mathrm{~h}$ in a convection oven.

2.3. PLA-g-MA. The grafting of PLA with the maleic anhydride was performed by mixing samples of $50 \mathrm{~g}$ of PLA and adding the 10 or $20 \%$ by weight of MA (with respect to the weight of the PLA) in a mixing chamber with a speed of $50 \mathrm{rpm}$ and a temperature of $170^{\circ} \mathrm{C} \mathrm{[39]} \mathrm{for} 20 \mathrm{~min}$ [19]. The initiator used was benzoyl peroxide (BPO), which has been proven to be a good reaction initiator for the MA and the PLA in quantities of $2 \%$ based on the weight of the MA [40, 41]. The content of MA grafted on the PLA was determined using the titration method as follows [42]: one gram of PLA-g-AM was dissolved in $150 \mathrm{ml}$ of chloroform, added to a $0.1 \mathrm{~N} \mathrm{HCl}$ solution, and then titrated with a $0.1 \mathrm{~N} \mathrm{KOH}$ solution using phenolphthalein as indicator.

The acid number and content of MA shall be calculated as follows:

$$
\operatorname{MA}(\%)=\frac{(\text { Acid number })(98.06)}{(2)(561)}
$$

where

$$
\text { acid number }\left(\frac{\mathrm{mg} \mathrm{KOH}}{\mathrm{g}}\right)=\frac{\left(\mathrm{ml}_{\mathrm{KOH}}\right)\left(\mathrm{N}_{\mathrm{KOH}}\right)(56.1)}{\text { grams of polymer }} \text {. }
$$

\subsection{Composite Mechanical Properties. The PLA-HENCEL} composites were formulated in accordance with the factorial design. The components, PLA, HENCEL, and the PLA-g$\mathrm{MA}$, were dried at $85^{\circ} \mathrm{C}$ for 6 hours before injection moulding to prevent any degradation due to hydrolysis. $2 \mathrm{~mm}$ thick, $80 \mathrm{~mm}$ by $80 \mathrm{~mm}$ specimens were injection moulded with an Arburg Allrounder 320C/600/250 injection moulding machine equipped with a screw of $35 \mathrm{~mm}$ in diameter. The injection pressure was 850 bars, while the applied holding pressure was 600 bars. The temperature profile used was $165-175-180-185-190^{\circ} \mathrm{C}$ from the hopper to the nozzle. Heat deflection temperature measurements were performed on Ceast HV3 type HDT (Torino, Italy) measuring equipment according to ISO 75 standard. HDT B type measurements were carried out in flatwise mode with a loading stress of $0.45 \mathrm{MPa}$, heating rate of $2^{\circ} \mathrm{C} / \mathrm{min}\left(120^{\circ} \mathrm{C} /\right.$ hour $)$, and a span length of $64 \mathrm{~mm}$. The mechanical properties of the composite specimens were analyzed by using tensile, flexural, and Charpy tests. The tensile and the flexural tests were performed by using a Zwick Z020 universal testing machine (Ulm, Germany) equipped with a Zwick BZ 020/TN2S force measuring cell with a force limit of $20 \mathrm{kN}$ and by using a crosshead speed of $5 \mathrm{~mm} / \mathrm{min}$. The Charpy impact tests were performed on unnotched samples by using a CEAST Resil Impactor (Torino, Italy) impact testing machine equipped with a $15 \mathrm{~J}$ impact energy hammer and a DAS8000 data collector unit. All of the tests were performed at room temperature at a relative humidity of $50 \pm 10 \%$. For the micromechanical analysis, the biocomposites were extruded in an Intelli-Torque Plasti-Corder, Brabender model 01-45000 (C.W. Brabender Instruments, Inc., Hackensack, NJ, USA), with a corotating two-screw extruder. The temperature
TABLE 1: Levels of factors in the experimental design.

\begin{tabular}{lcc}
\hline Levels & \multicolumn{2}{c}{ Factor } \\
& $\begin{array}{c}\text { Maleic anhydride, } \\
\text { MA (\% w/w) }\end{array}$ & $\begin{array}{c}\text { HENCEL content } \\
(\%)\end{array}$ \\
\hline Lower $(-1)$ & 1 & 10 \\
Higher $(+1)$ & 2.5 & 20 \\
\hline
\end{tabular}

profile used was $175^{\circ} \mathrm{C}, 180^{\circ} \mathrm{C}, 180^{\circ} \mathrm{C}, 180^{\circ} \mathrm{C}$, and $175^{\circ} \mathrm{C}$ in each of the zones and $170^{\circ} \mathrm{C}$ in the flat die.

2.5. Infrared Spectroscopy (FTIR). A FTIR analysis of the PLA-g-MA was performed on a Nicolet model Protege 460 Magna IR (Nicolet Inst. Corp., Madison, WI, USA) spectrometer using a photoacoustic attachment (MTEC Photoacoustics, Inc., Ames, IA, USA). The spectra were recorded with 60 scans: $4 \mathrm{~cm}^{-1}$ resolution and a speed of $0.15 \mathrm{~cm} / \mathrm{s}$.

2.6. Scanning Electron Microscopy. The composite tensile fracture surfaces were coated with gold and then analyzed using a JEOL JSM-6360LV (JEOL de Mexico, Mexico City, Mexico) scanning electron microscope operated at $20 \mathrm{keV}$.

2.7. Factorial Design Methodology. A common method used to investigate the effects of the values of the operational parameters (factors) on a process is the usual approach of changing the value of one factor at a time and noting its influence on a given characteristic of the final product (response). However, this method has some disadvantages: it requires a large number of trials and it does not reveal the possible interactions between factors. In contrast, factorial experimental designs can be efficient when several factors (more than two) are under study. By factorial design, in each complete trial, all possible combinations of the levels of the factors are investigated. The factors are commonly used at two levels. Normally, it is assumed that the response is approximately linear over the range of the factor level chosen.

A two-level full factorial design $2^{2}$ with two central points was employed to investigate and study the effect of microfibrillated henequen cellulose (HENCEL) and PLA-gMA coupling agent contents on the tensile, flexural, and impact mechanical properties and the HDT of biodegradable PLA composites.

The levels of the two independent variables studied are indicated in Table 1. A statistical analysis of the data was performed using the commercial software Design-Expert 7, (Stat-Ease, Inc., Minneapolis, MN, USA). The analysis of variance (ANOVA) provided a study of the variation present in the results of experiments carried out and the test of statistical significance, $P$ value, was determined according to the total error criteria considering a confidence level of $95 \%$. The influence of a factor will be significant if the value of critical level $(P)$ is lower than 0.05 , discarding the meaningless parameters for $P$ values over 0.05 [43]. 


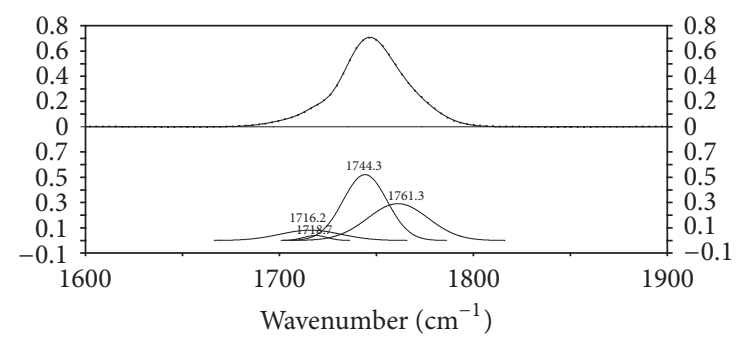

(a)

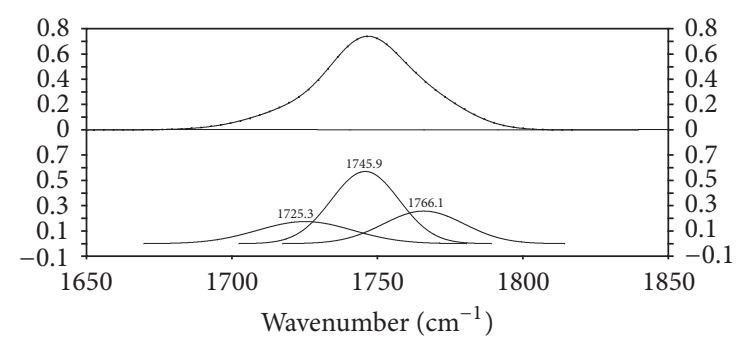

(b)

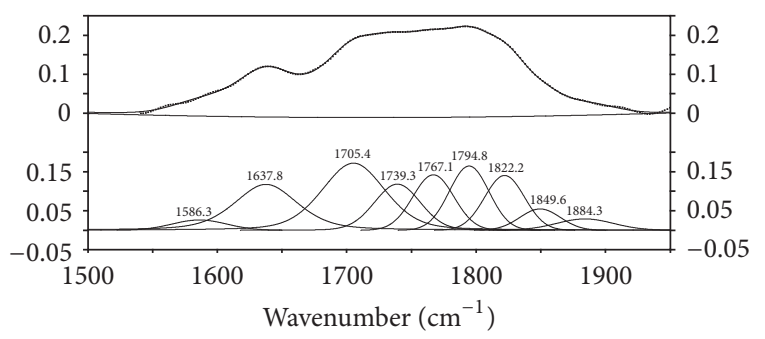

(c)

FIGURE 1: FTIR spectra of poly(lactic acid) $3251 \mathrm{D}$ pristine and grafted with maleic anhydride (PLA-g-MA) (a) PLA3251D.csv: Pk = Gauss Amp 4 Peaks; Bg = Quadratic; $r^{2}=0.999868 ; \mathrm{SE}=0.0023849$; $F=$ 40098.7. (b) PLA3251D-g-AM 10\%: Pk = Gauss Amp 3 Peaks; $\mathrm{Bg}=$ Cubic; $r^{2}=0.999971 ; \mathrm{SE}=0.00150788 ; F=104650$. (c) PLA3251D-g-AM 20\%.csv: Pk = Gauss + Lor Amp 9 Peaks; Bg = Quadratic; $r^{2}=0.999411 ; \mathrm{SE}=0.00210295 ; F=7770.34$.

\section{Results and Discussions}

3.1. PLA-g-MA. PLA was grafted with $10 \%$ and $20 \% \mathrm{w} / \mathrm{w}$ maleic anhydride (MA) and FTIR analysis was performed to assess the presence of functional groups on the functionalized PLA-AM for each of the different mixtures [39]. Two graphs for each of them can be seen in Figures 1(a)-1(c). The characteristic absorption peak of the stretching of the carbonyl group $\mathrm{C}=\mathrm{O}$, around $1745 \mathrm{~cm}^{-1}$, is shown for the pristine PLA in the upper curve of Figure 1(a). Also, at the lower curve, the deconvolution characteristic peaks corresponding to PLA transitions features are shown $[40,41]$. On the other hand, the results for PLA-g-AM 10\% and PLA-g-AM 20\% are shown in Figures 1(b) and 1(c), respectively. In these graphs, the presence of PLA-AM grafted on different percentages by weight of the PLA was confirmed by means of the deconvolution of the absorbance peaks, using a commercial software Peakfit ${ }^{\circledR}$ (Systat Software Inc., San Jose, CA, USA), as can be seen in the lower curves $[31,32]$. Cyclic anhydrides should exhibit an intense absorption band near $1790 \mathrm{~cm}^{-1}$
TABLE 2: Content of MA grafted on PLA.

\begin{tabular}{lc}
\hline Sample & \% MA grafted \\
\hline PLA-g-MA 10 & 1 \\
PLA-g-MA 20 & 2.5 \\
\hline
\end{tabular}

and a weak absorption near $1850 \mathrm{~cm}^{-1}$ due to the symmetric and asymmetric stretching of $\mathrm{C}=\mathrm{O}$. It should be noted that the absorbance at $1850 \mathrm{~cm}^{-1}$ (asymmetrical stretching $\mathrm{C}=\mathrm{O}$ ) was only evident in Figure 1(c) corresponding to PLA grafted with $20 \%$ AM. In the literature, a similar behavior was reported by Zhu [39], Detyothin et al. [42], and Avella et al. [44]. The MA content on the PLA-g-MA determined by the titration method is shown in Table 2 .

\subsection{Effects Estimated Using the Analysis of Variance (ANOVA).} The analysis of variance (ANOVA) of the experimental data was carried out using the Design-Expert 7 statistical software and the results are summarized in Table 3.

The values of $P<0.05$ indicate a statistical significance in the terms of the model, while the statistical relationship between the selected variable and the response variable has a 95\% level of confidence when the $P$ value for the model is below 0.05 . The $P$ value of the model for the two types of adhesives was much lower than $0.05(<0.00001)$, indicating that the statistical model is adequate. In can be seen in Table 3 that practically all the principle effects of the factors had a value of $P<0.05$, indicating that both factors HENCEL and MA are statistically significant for the tensile, flexural, HDT, and impact strength properties of PLA composites. Regarding the interaction between the principle effects, MA-HENCEL, there are differences with respect to the mechanical property; for example, for tensile and flexural mechanical properties, there is a synergistic effect between MA and HENCEL, whereas for HDT and impact strength there is not any statistical evidence of synergistic effect between both factors. Goodness of fit was revised by means of the coefficient of determination $\left(R^{2}\right)$. In this work, the coefficient of determination remained between 0.84 and 0.96 for all mechanical properties, implying that the statistical model presented good behavior. In addition, the values of adjustment of the coefficient of determination ranged between 0.74 and 0.93 , which provides information as to how well the model predicts a response value.

3.3. Normal Plots of Residuals. The analysis of residuals is one way of measuring the validity of the experimental design. The plots of residuals for the tensile elastic modulus and the tensile strength are presented in Figures 2(a) and 2(b). In these figures, one can observe that the residuals present a normal behavior for both types of tests and both adhesives. The data points on the straight line confirm the normality and independence of the residuals.

In Figures 3(a) and 3(b), the residual plots for the flexural elastic modulus and flexural strength can be seen. In this figure, one can observe that the residuals present a 


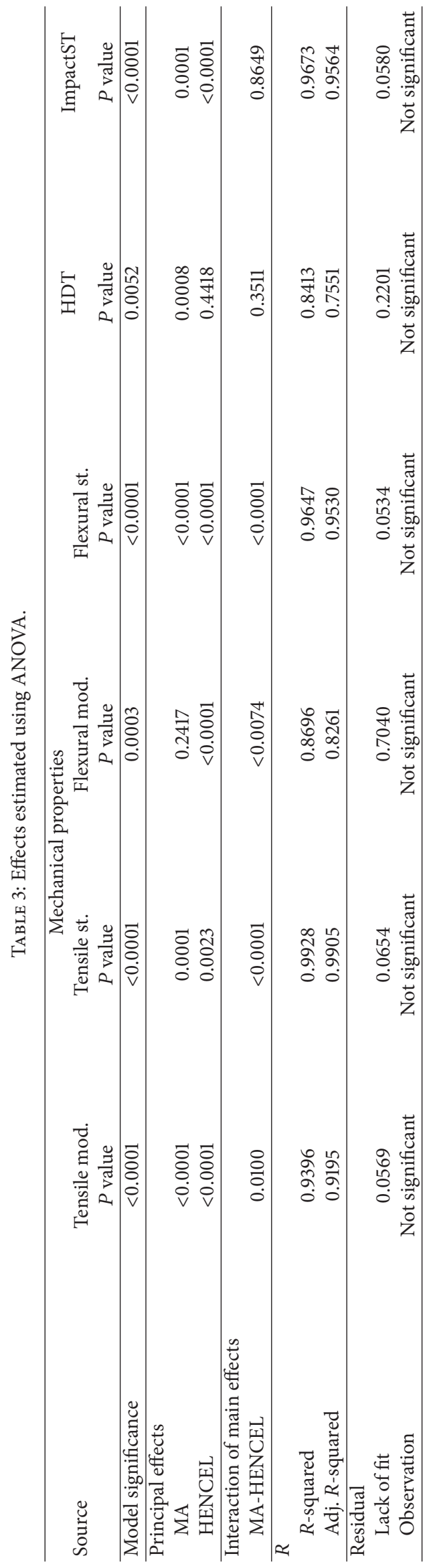




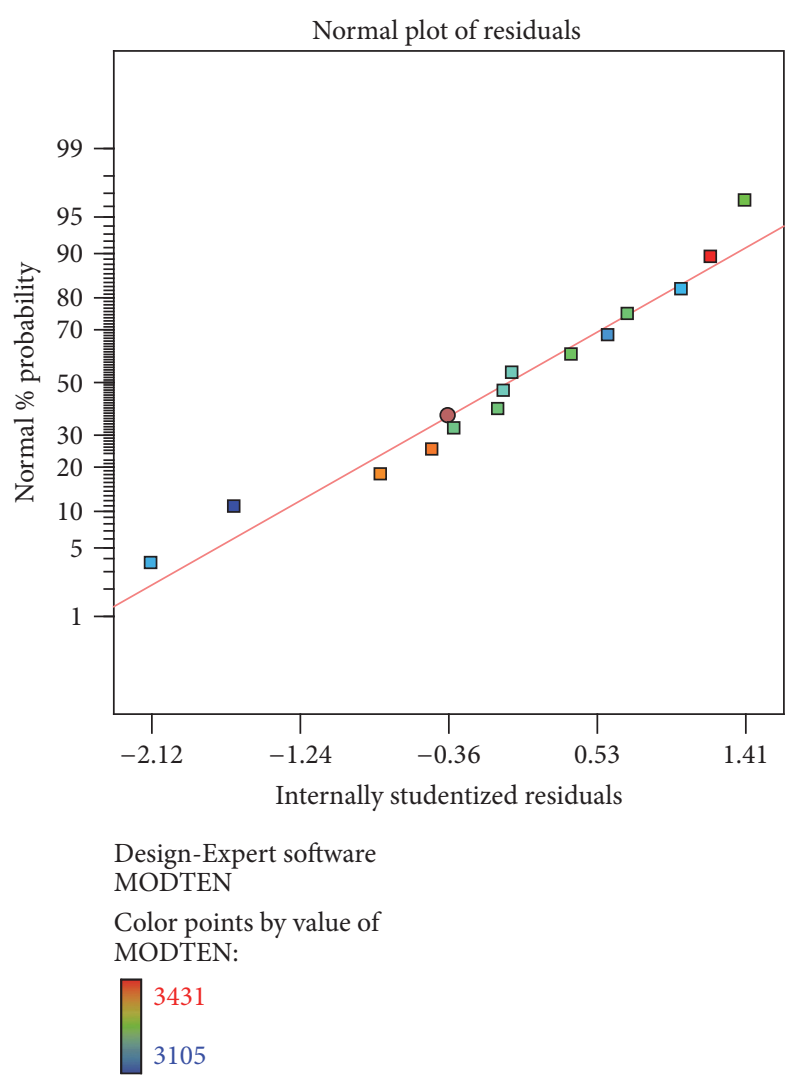

(a)

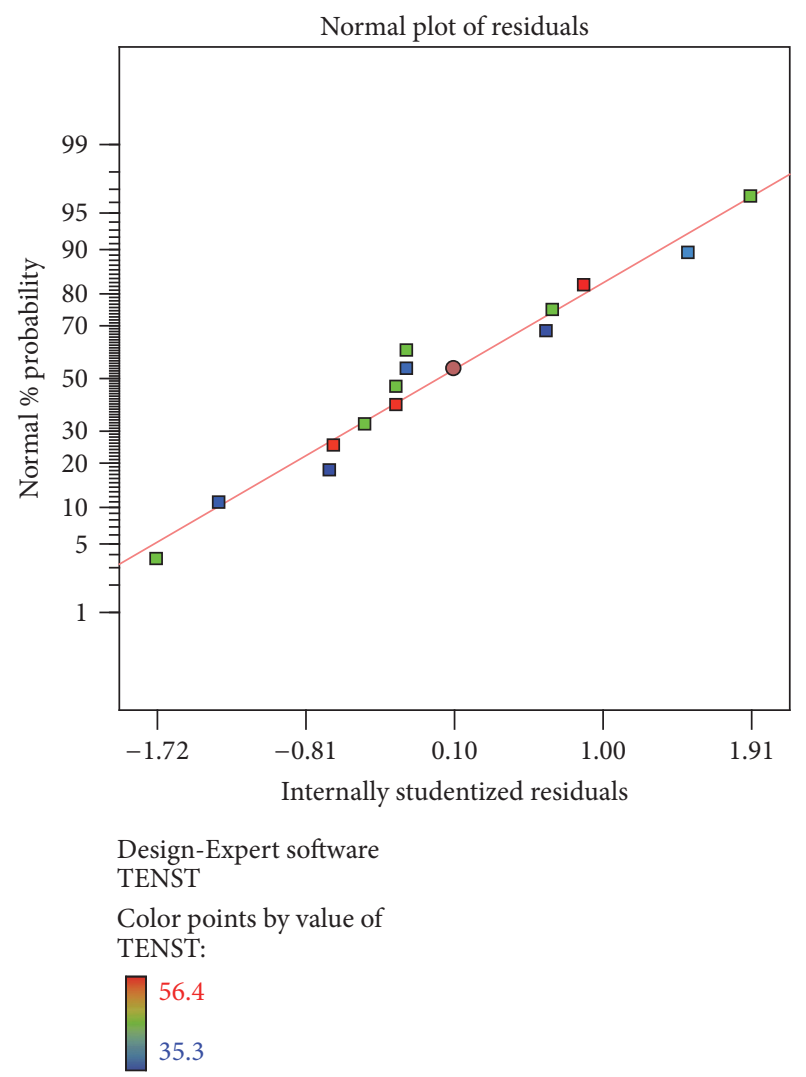

(b)

FIGURE 2: Residuals for tensile mechanical properties.

normal behavior for both properties. The data points on the straight line confirm the normality and independence of the residuals.

On the other hand, in Figure 4(a), the plot for the HDT residuals is shown, whereas the residuals for the Charpy impact strength are presented in Figure 4(b). In both cases, it can be seen that the residuals have a normal behavior.

3.4. Predicted versus Calculated Response Plots. Another form of evaluating goodness of fit of the regression model is by comparing the experimental data with those predicted by the model. In Figure 5, we can observe that there exists a very good correlation between the experimental data and data calculated with the statistical model for both tensile modulus and tensile strength, since the points are very close to the diagonal.

In Figure 6, we can observe that there exists a very good correlation between the experimental data and data calculated with the statistical model for both flexural modulus and flexural strength, since the points are very close to the diagonal.

In Figure 7(a), we can observe that there is a good correlation between the experimental data and data calculated with the statistical model for HDT and a better one in the case of Charpy impact strength as can be seen in Figure 7(b).
3.5. Interaction Plots. As can be seen in the results of the analysis of variance (ANOVA) shown in Table 3, the interaction between the MA and the HENCEL was statistically significant for tensile and flexural mechanical properties and not significant for HDT and Charpy impact strength. The statistical significance of the interaction term suggests that there is a synergy between the PLA-g-Ma coupling agent and the microfibrillated henequen cellulose fiber. In Figure 8, the interaction plot for Charpy impact strength is shown. As can be seen, the lines are parallel and this suggests that the effect of increase of MA from 1 to $2.5 \%$ is independent of the HENCEL content in the composite. In this case, the Charpy impact strength drops about $7 \%$ at $10 \%$ HENCEL content and $8 \%$ when HENCEL loading is $20 \%$. On the other hand, the effect of HENCEL content is independent of MA too. At 1\% MA, the impact strength drops $17 \%$ when HENCEL changes from $10 \%$ to $20 \%$ and drops $18 \%$ when MA is $2.5 \%$. This suggests that there is no synergistic effect between MA and HENCEL.

The interaction plots for tensile and flexural mechanical properties are shown in Figure 9. It is evident in Figure 9 that the lines are not parallel; even in the case of plots in Figures 9 (b) and 9 (d) the lines cross each other. This behavior is typical of synergistic or antagonistic effects. In the case of both tensile and flexural moduli, the lines tend to come together or approach as the MA content increases. This means 

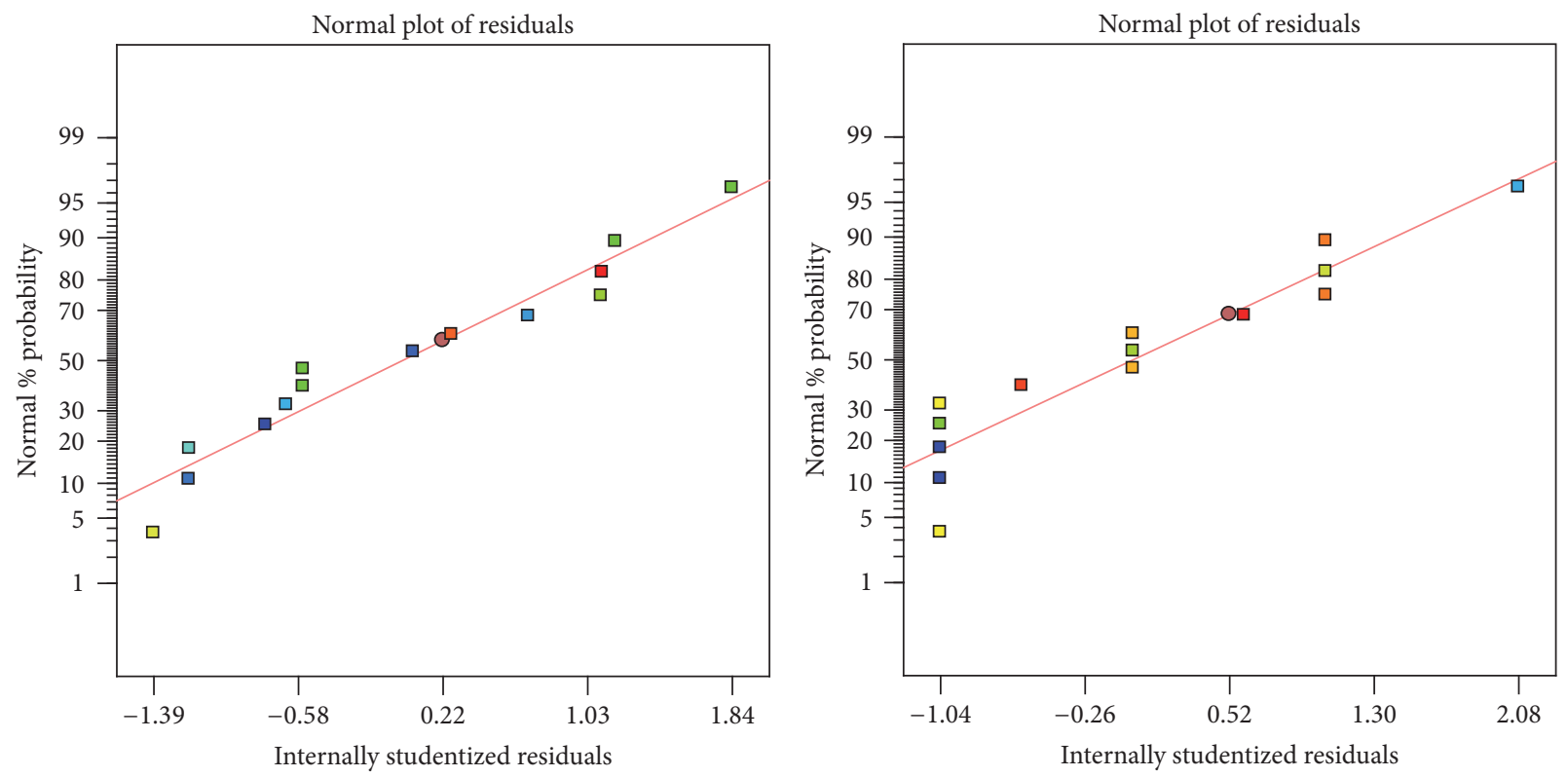

Design-Expert software

MODFLEX

Design-Expert software

FLEXST

Color points by value of

Color points by value of MODFLEX:

FLEXST:

4437

3882

П 71

(a)

(b)

FIGURE 3: Residuals for flexural mechanical properties.
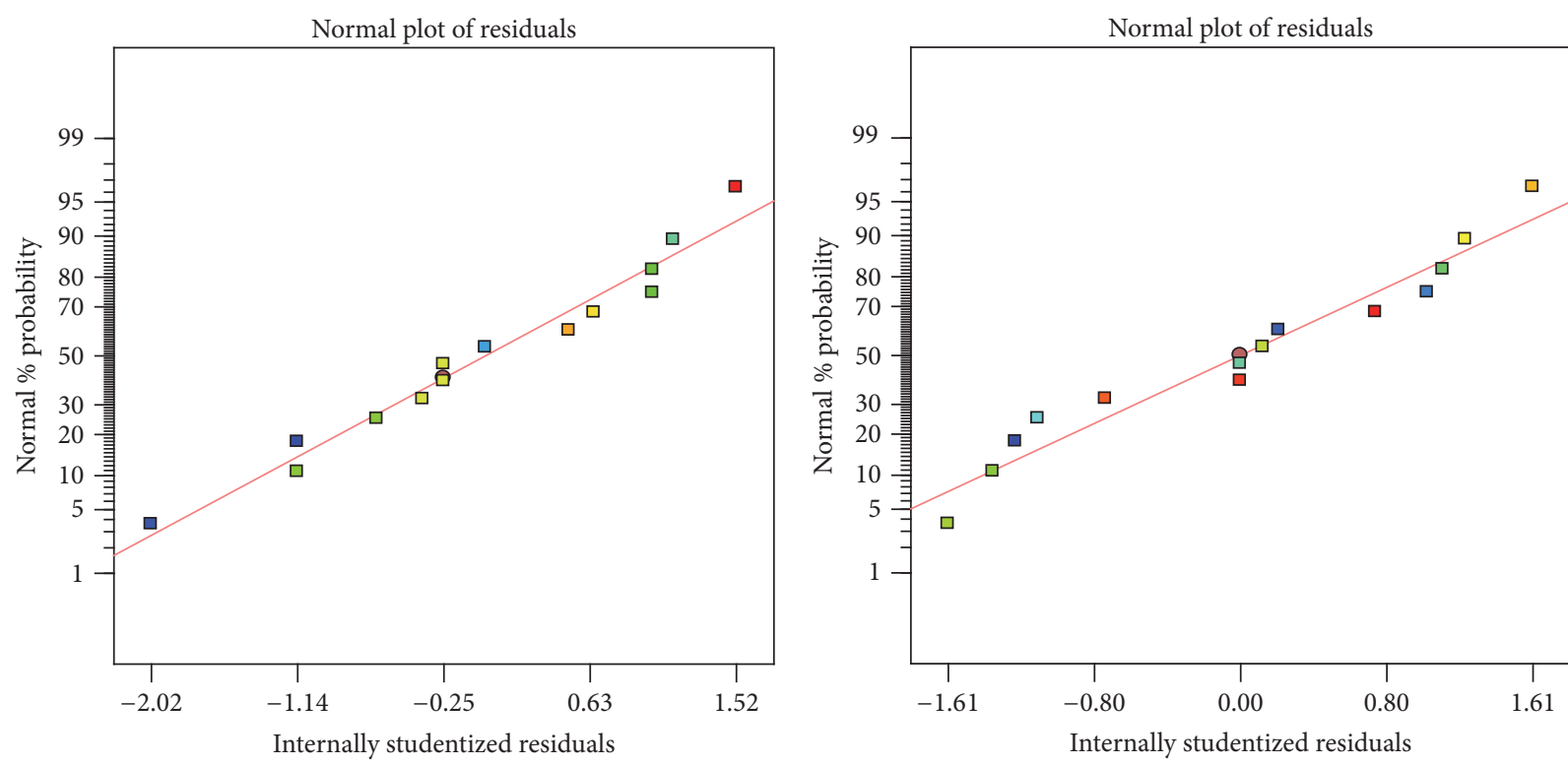

Design-Expert software

HDT

Color points by value of

HDT:

Design-Expert software

ImpactST

Color points by value of ImpactST:

$$
\begin{aligned}
& 55.6 \\
& 53.8
\end{aligned}
$$

16.6

12

FIGURE 4: Residuals for (a) HDT and (b) Charpy impact strength. 


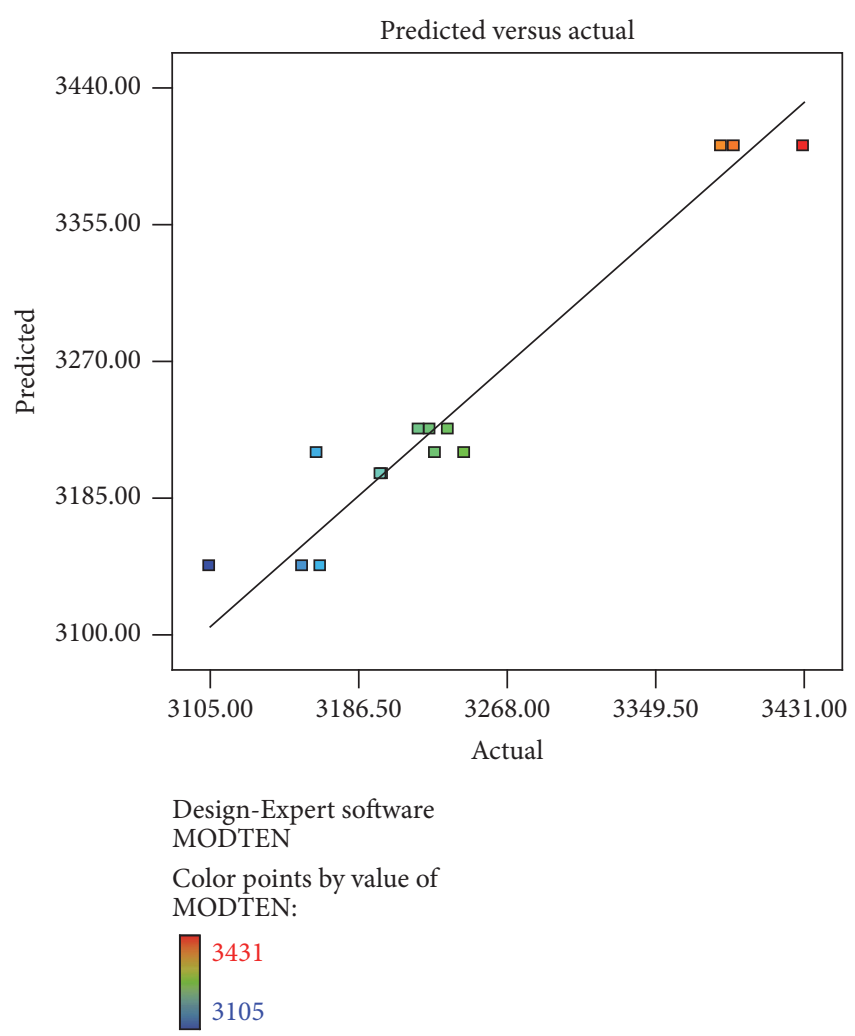

(a)

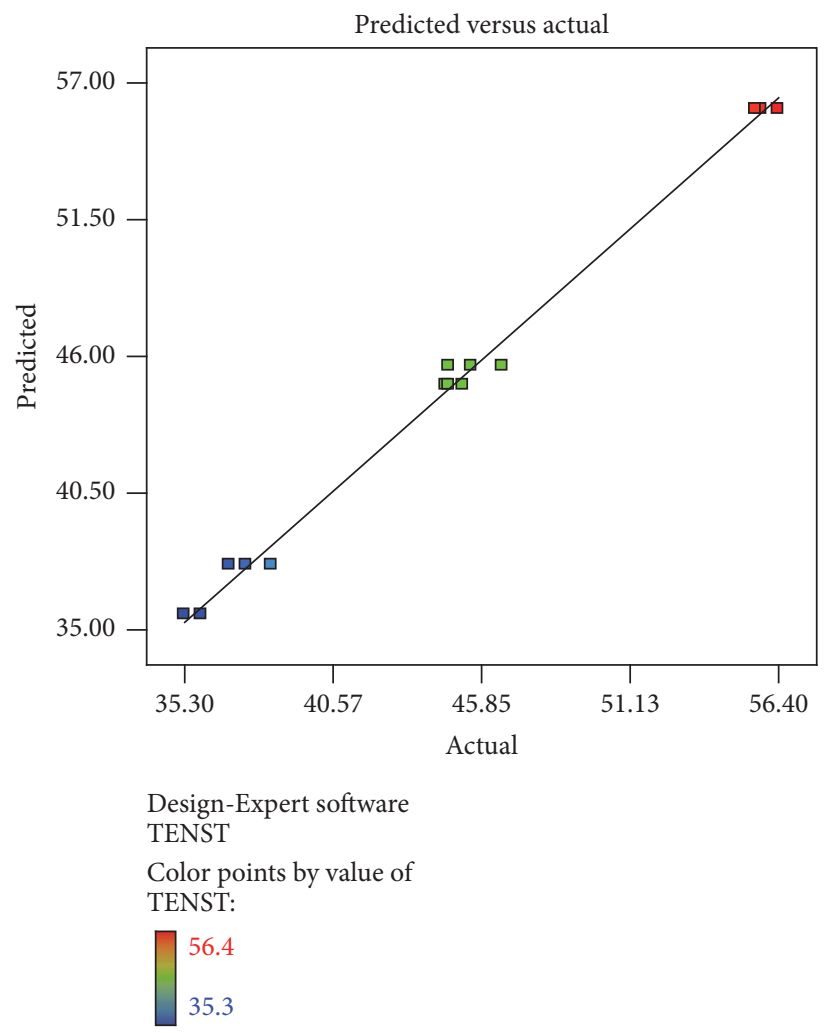

(b)

Figure 5: Predicted versus experimental data for tensile mechanical properties.

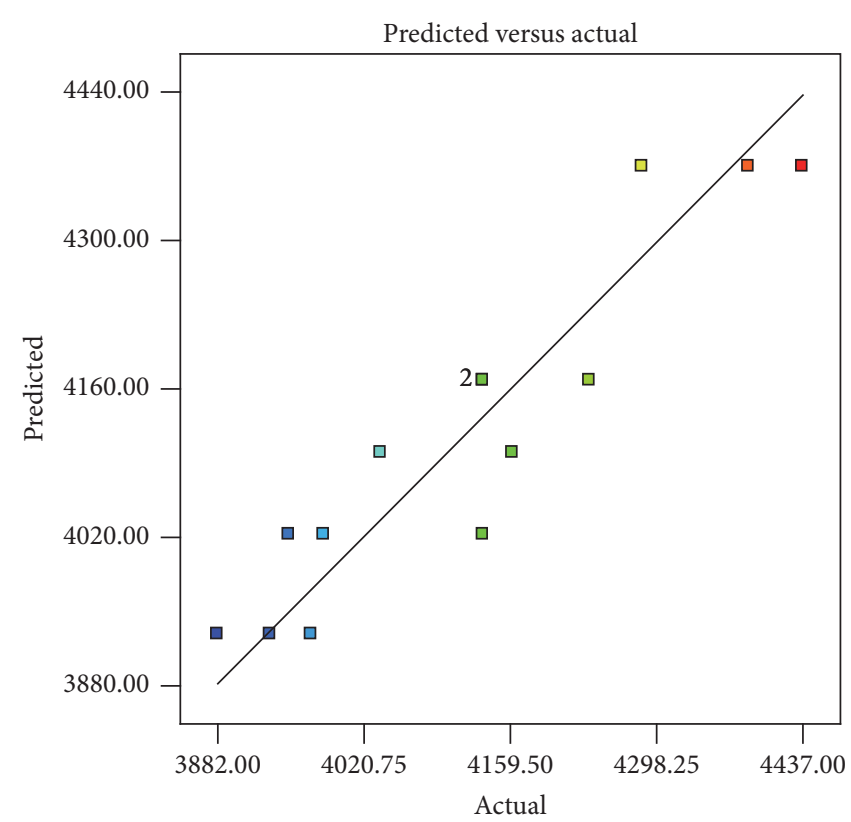

Design-Expert software MODFLEX

Color points by value of MODFLEX:

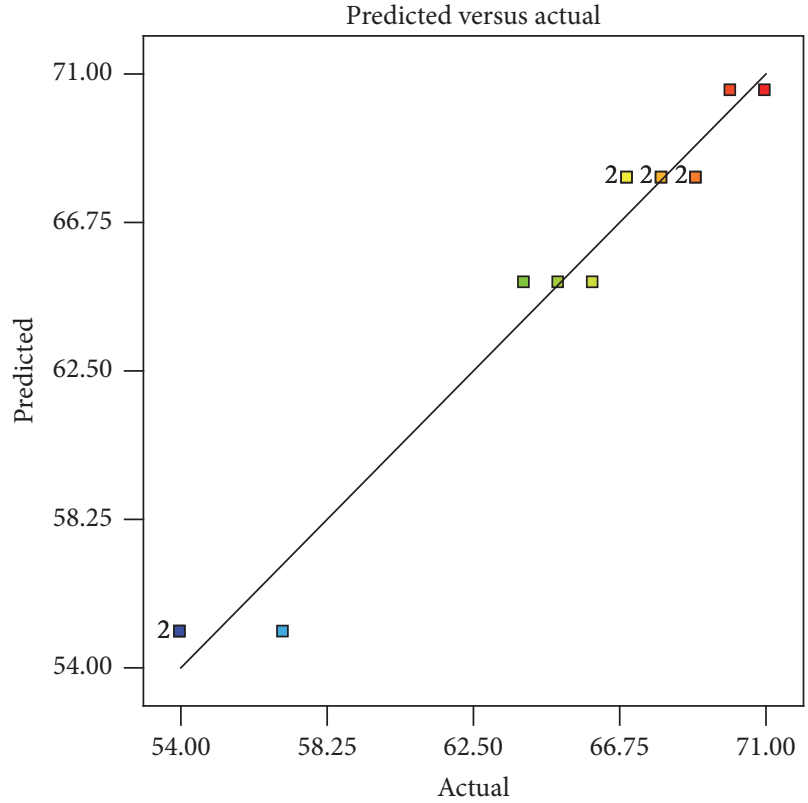

Design-Expert software FLEXST

Color points by value of FLEXST:

FIgURE 6: Predicted versus experimental data for flexural mechanical properties. 


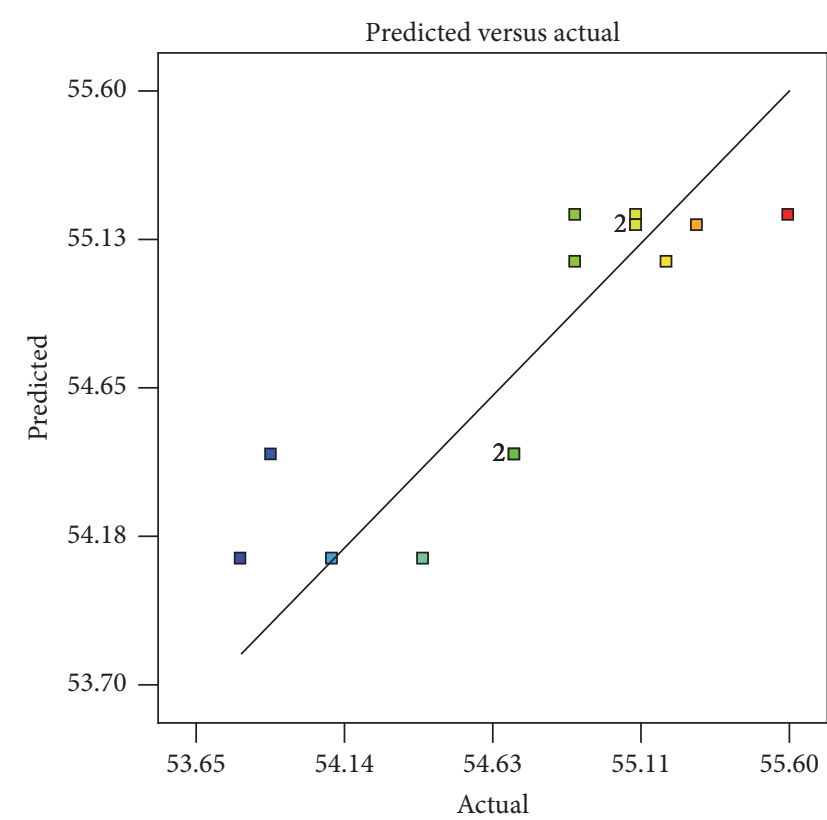

Design-Expert software HDT

Color points by value of HDT:

55.6 53.8

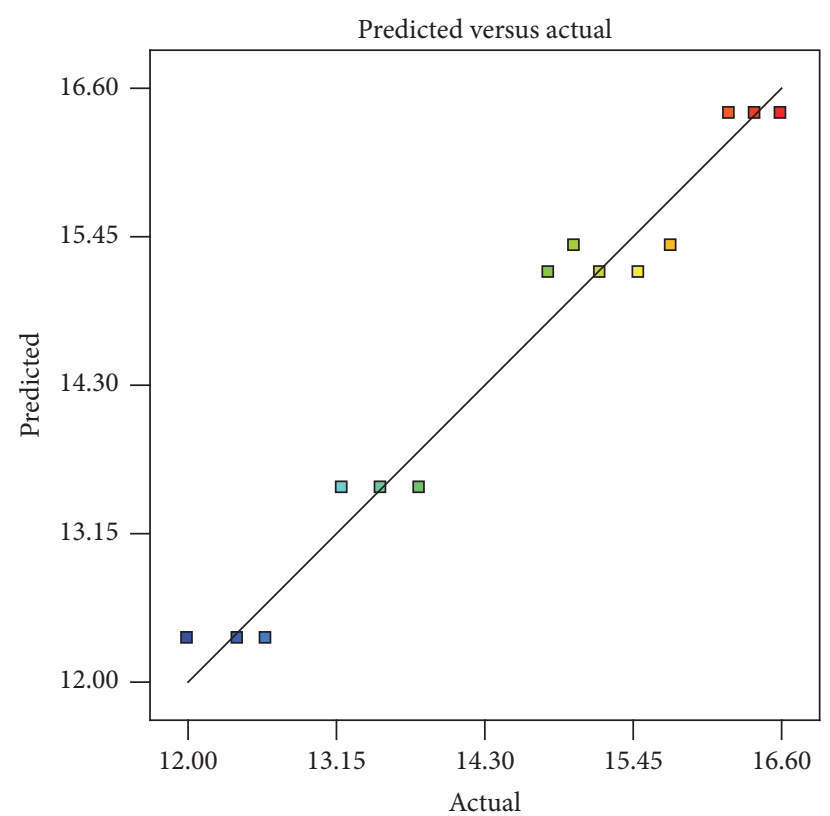

Design-Expert software ImpactST

Color points by value of ImpactST:

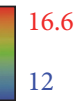

(a)

(b)

FIgURE 7: Predicted versus experimental data for (a) HDT and (b) Charpy impact strength.

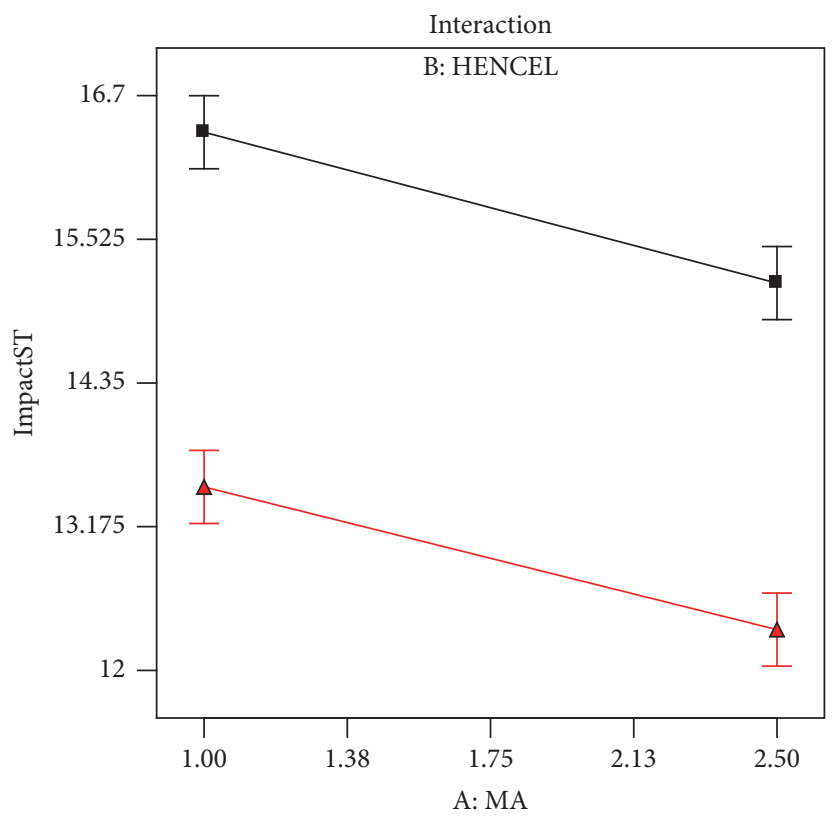

Design-Expert software ImpactST
- $\mathrm{B}-10.000$
$\mathrm{X} 1=\mathrm{A}: \mathrm{MA}$
$\Delta \mathrm{B}+20.000$
$\mathrm{X} 2$ = B: HENCEL

FIGURE 8: Interaction plots for Charpy impact strength. 

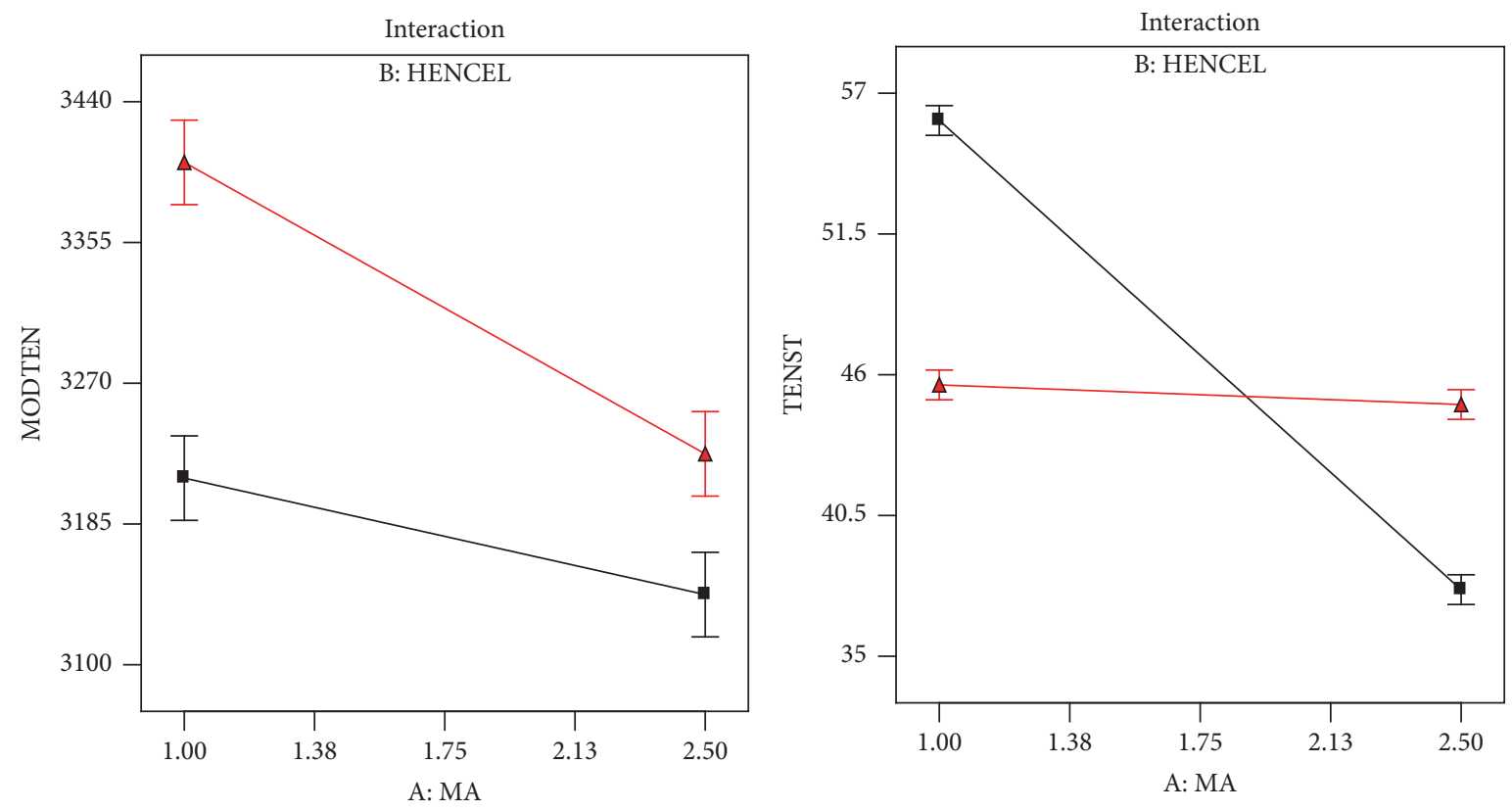

Design-Expert software Design-Expert software MODTEN TENST
- $\mathrm{B}-10.000$
$\Delta \mathrm{B}+20.000$

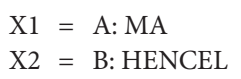
$\mathrm{X} 2$ = $\mathrm{B}:$ HENCEL

(a)

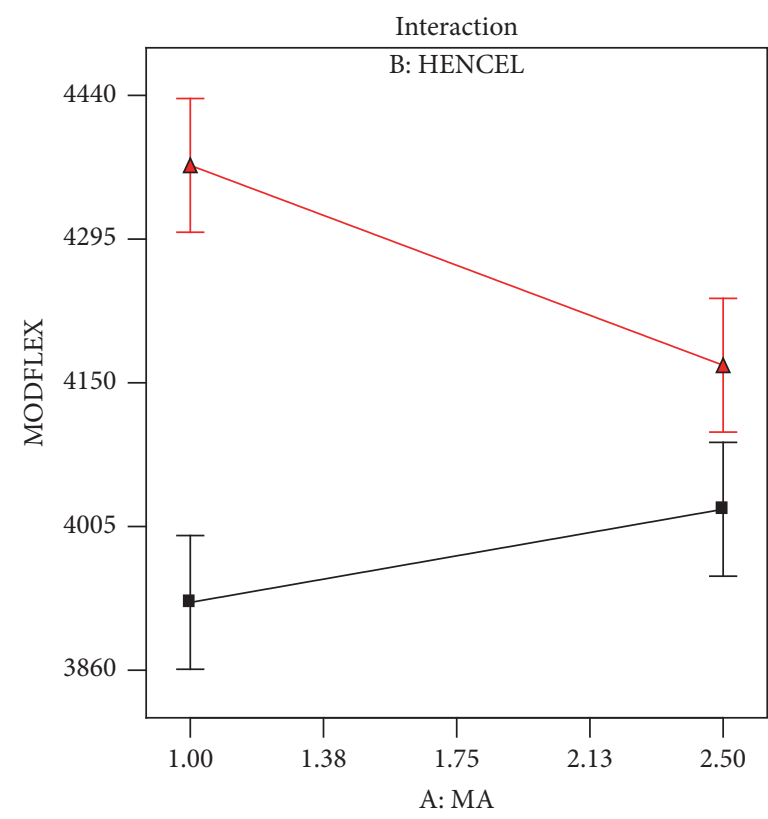

Design-Expert software MODFLEX

- B- 10.000

$\Delta \mathrm{B}+20.000$

(c)
$\mathrm{X} 1=\mathrm{A}: \mathrm{MA}$

$\mathrm{X} 2=\mathrm{B}:$ HENCEL

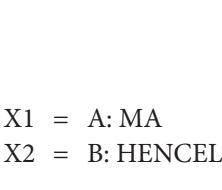

- $\mathrm{B}-10.000$

$\Delta \mathrm{B}+20.000$
$\mathrm{X} 1=\mathrm{A}: \mathrm{MA}$

$\mathrm{X} 2=\mathrm{B}:$ HENCEL

(b)

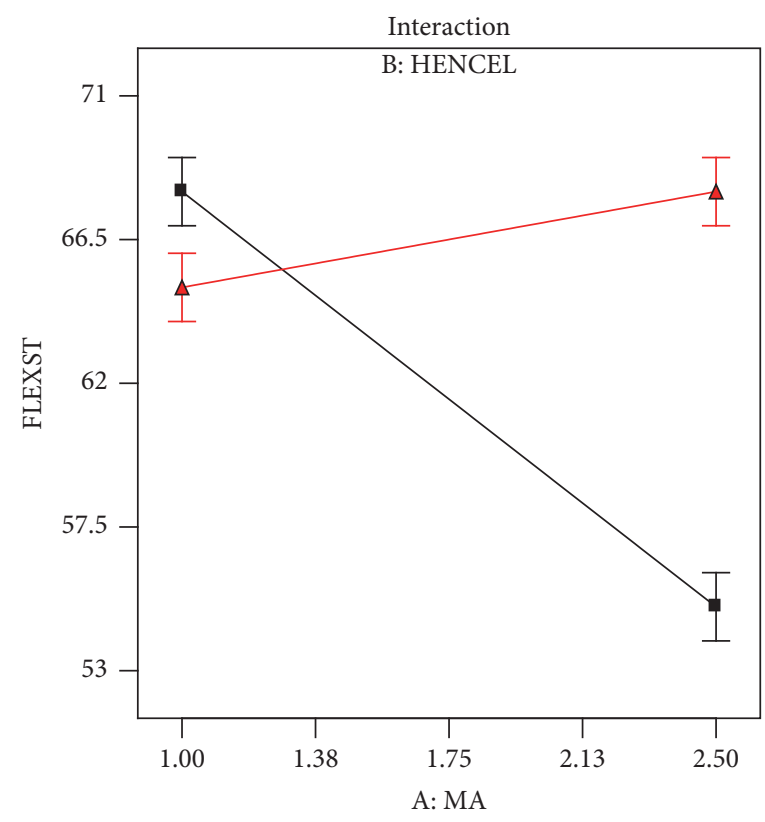

Design-Expert software FLEXST

- B- 10.000

$\Delta \mathrm{B}+20.000$

$\mathrm{X} 1=\mathrm{A}: \mathrm{MA}$

$\mathrm{X} 2$ = B: HENCEL

(d)

FIGURE 9: Interaction plots for tensile $(a, b)$ and flexural $(c, d)$ mechanical properties. 
that the effect of the MA content depends on the HENCEL loading. For example, in the case of flexural modulus at $10 \%$ of HENCEL, the modulus rises as MA increases, whereas at $20 \%$ of HENCEL the modulus drops when the MA content changes from $1 \%$ to $2.5 \%$. Also, at low values of MA (1\%), the modulus is $11 \%$ higher for HENCEL $20 \%$ compared to HENCEL $10 \%$, whereas at high values of MA the modulus decreases $5 \%$ when HENCEL changes from $10 \%$ to $20 \%$. This behavior has the same trends in the case of tensile mechanical properties.

3.6. Micromechanical and Morphological Analysis. The tensile strength and elastic modulus for PLA composites as a function of HENCEL and for three different MA amounts are shown in Figures 10(a) and 10(b), respectively. It is observed that the strength decreases steeply for the $1 \%$ and also for $1.75 \%$ MA. It is also observed that the composite tensile strength is lower with increasing microfibrillated cellulose fibers content. An increase is observed for the $2.5 \% \mathrm{MA}$ as a function of microfibrillated cellulose. Then, the efficiency of the $1 \%$ and $1.75 \%$ PLA-g-MA as a coupling agent does not seem to be appropriate and there seems to be an increase of the tensile strength as a function of HENCEL content only with the larger amount of $2.5 \% \mathrm{MA}$.

However, the value of the tensile strength relative to the strength of the matrix is approximately 50\%. The amount of coupling agent present on the composite material was estimated as a function of weight of the fiber. Therefore, it can be said that the amount of the coupling agent in the composite increases with increasing the amount of microfibrillated cellulose. It has been reported that the presence of MA results in a considerable decrease of the polymer viscosity, indicating the occurrence of chain scission reactions and a degrading effect of MA and chain extension in the presence of peroxide [45].

In the case of the elastic modulus, a nonlinear behavior is observed with increasing content of microfibrillated cellulose but there is only a slight increase for the $1.75 \% \mathrm{MA}$ with respect to the $1 \% \mathrm{MA}$. A similar trend is observed for the 2.5\% MA composite but with lower elastic modulus than the other two formulations. Again, this gives an indication of PLA degradation with increasing content of grafted MA.

The effect of reinforcement on the strength and stiffness of the composite can be expressed quantitatively with the help of an appropriate model. A model developed to describe the composition dependence of the tensile strength of particulate filled and short fiber reinforced polymer composite, simplified for small deformations, can be expressed as [46]

$$
\sigma_{c}=\sigma_{0} \frac{1-V_{f}}{1+2.5 V_{f}} e^{B V_{f}}
$$

where $\sigma_{c}$ and $\sigma_{0}$ are composite and matrix strength, respectively, $V_{f}$ is the volume fraction of the reinforcing fiber in the composite, and $B$ is a parameter expressing reinforcement and is related to interfacial adhesion. The model takes into account the effect of matrix properties $\left(\sigma_{0}\right)$.

The elastic Modulus was estimated using a model proposed by Nairn et al. [47] using the following equation:

$$
E_{c}=E_{f}\left[1-\frac{\tanh (\eta L / 2)}{\eta L / 2}\right] V_{f}+\left(1-V_{f}\right) E_{m}
$$

where

$$
\eta=\left[\frac{2}{r^{2} E_{f} E_{m}}\left[\frac{E_{f} V_{f}+\left(1-V_{f}\right) E_{m}}{\left(1-V_{f}\right) / 4 G_{f}+\left(1 / 2 G_{m}\right)\left[\left(1 /\left(1-V_{f}\right)\right) \ln \left(1 /\left(V_{f}+\chi\right)\right)-1-\left(1-V_{f}\right) / 2\right]+1 / r D_{s}}\right]\right]^{1 / 2}
$$

where $E$ refers to the elastic modulus, $V$ is the volume fraction, the subscripts $c, m, f$ refer to composite, matrix, and fiber, respectively, and the parameter $\chi$ is a constant added to correct for a problem in the use of shape functions which gives a $\ln \left(1 / V_{f}\right)$ term in the denominator of (5). Without $\chi$ the denominator of (5) would approach infinity as $V_{f} \rightarrow 0$. From shear-lag predictions and a finite element analysis for both isotropic and anisotropic fibers at various $E_{f} / E_{m}$ ratios, a universal value of $\chi=0.009$ was determined. The presence of an interface is given by the parameter $D_{s}$ in the shear-lag equation, and it is possible to characterize the improvement in interfacial adhesion with the addition of coupling agents; if perfect adhesion is assumed, $D_{s}=\infty$.

Excellent agreement was obtained between the measured and the estimated values for both the composite tensile strength and the elastic modulus and only slight deviations were noticed for high microfibrillated cellulose fibers content. With the use of appropriate values of matrix strength and stiffness and considering the improved fiber-matrix adhesion because of the coupling agent by using appropriate values for $D_{s}$, the mechanical models yield a good agreement between the experimental and the estimated values.

In order to find out some microscopic evidence of the PLA-g-MA coupling agent efficiency, SEM inspection of the fracture surfaces of the tensile specimens for 90/10 PLA/HENCEL composites was carried out. It is evident in Figure 11(a) that in the specimen without PLA-g-MA coupling agent there are many unbounded and pulled-out fibers. This behavior suggests a weak interfacial adhesion and poor compatibility of the composites without the coupling agent. On the other hand, in the specimen with the PLAg-MA coupling agent more fibers seem to be still coated with the matrix resin and little fiber pull-out is observed, indicating improved fiber-matrix adhesion, as can be seen in Figure 11(b). Moreover, the microfibrillated cellulose fibers seem to be preferentially oriented in the direction of the processing flow and a few air bubbles are also noticed, especially for composites with PLA-g-MA coupling agent. 


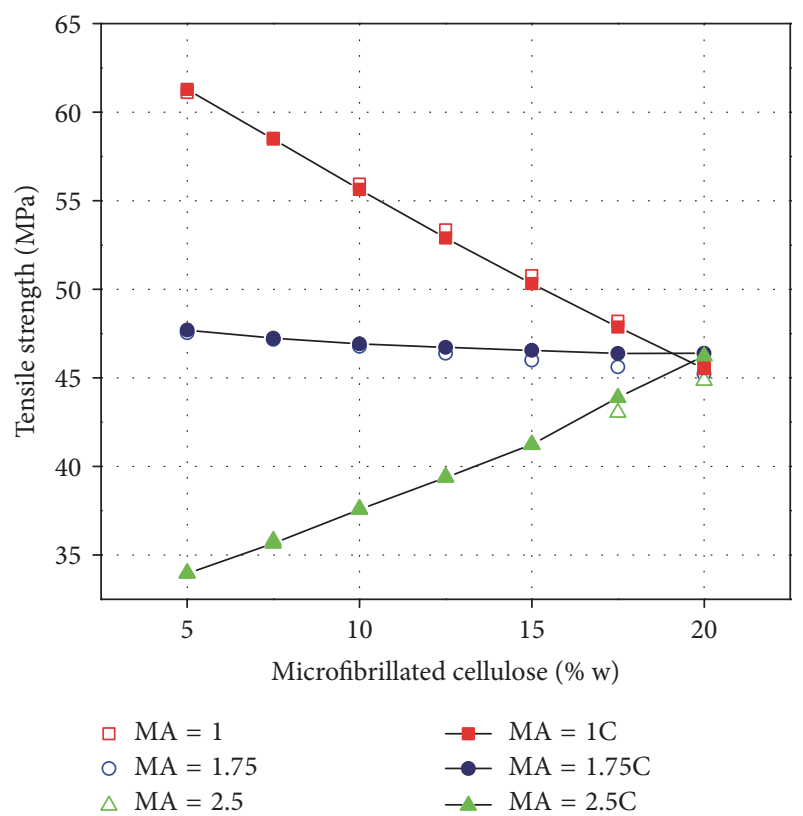

(a)

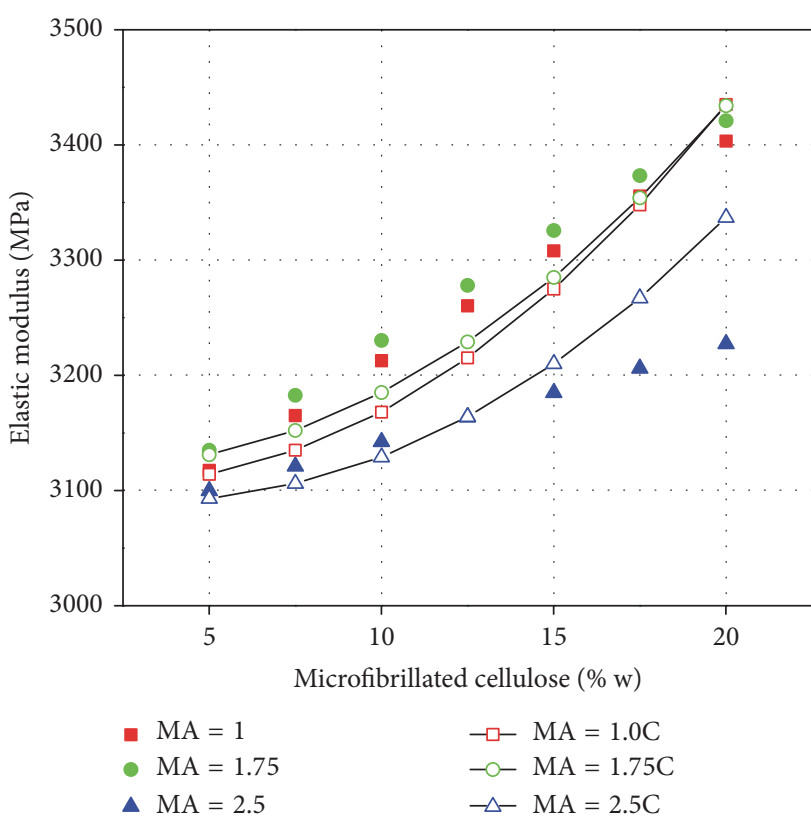

(b)

FIGURE 10: Tensile strength (a) and elastic modulus of biocomposites with different concentrations of PLA-g-MA and HENCEL.

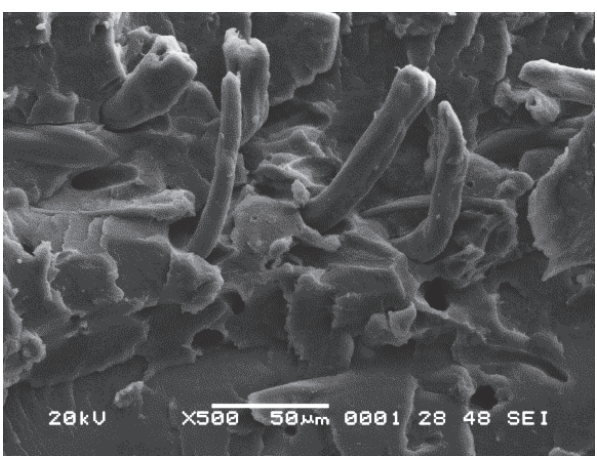

(a)

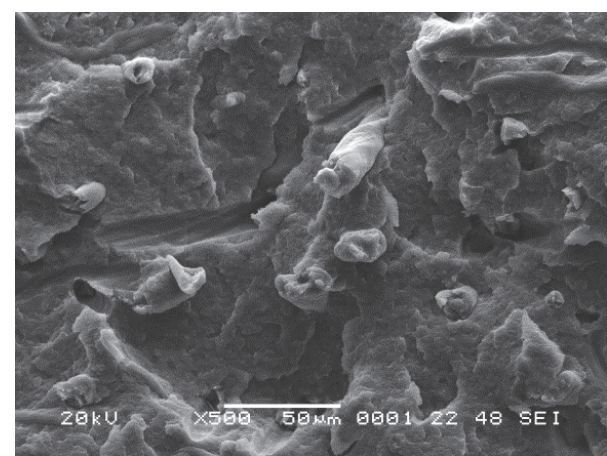

(b)

Figure 11: Fracture surface micrographs for 90/10 w/w PLA/HENCEL composites: (a) without and (b) with PLA-g-MA coupling agent.

\section{Conclusions}

In this work, a $2^{2}$ factorial design was used to study the effect of microfibrillated henequen cellulose (HENCEL) and PLA-g-MA coupling agent contents on the tensile, flexural, and impact mechanical properties and the heat deflection temperature (HDT) of biodegradable PLA composites.

The results had shown that principal effects of HENCEL and MA are statistically significant for the tensile, flexural, HDT, and impact strength properties of PLA composites. Regarding the interaction between the principle effects, MA-HENCEL, there are differences with respect to the mechanical property; for example, for the tensile and flexural mechanical properties, there is a synergistic effect between MA and HENCEL, whereas for HDT and impact strength there is not any statistical evidence of synergistic effect between both factors. Also it was found that the statistical model was suitable to describe the mechanical properties of PLA-HENCEL biocomposites.

The micromechanical analysis shows an excellent agreement between the measured and the estimated values for both the composite tensile strength and the elastic modulus and only slight deviations were noticed for high microfibrillated cellulose fibers content. The morphological analysis via SEM indicated that the addition of PLA-g-MA improved the fibermatrix adhesion because of the HENCEL unbounding and pull-out decreases from the PLA matrix. The use of appropriate values of matrix strength and stiffness and considering the improved fiber-matrix adhesion of the coupling agent yield a good agreement between experimental and estimated values. 


\section{Conflicts of Interest}

The authors declare that there are no conflicts of interest.

\section{Acknowledgments}

The authors would like to acknowledge the support from the Bilateral Cooperation Mexico (CONACYT)-Hungary (HAS) Program through Grant no. 193207 and from the Consejo Nacional de Ciencia y Tecnología (CONACYT) through Grant no. CB2013-220000. Also, the authors would like to thank Ms. I. Q. Silvia Beatriz Andrade Canto for the SEM micrographs and Maria V. Moreno-Chulim for carrying out the FTIR measurements.

\section{References}

[1] M. Rose and R. Palkovits, "Cellulose-based sustainable polymers: state of the art and future trends," Macromolecular Rapid Communications, vol. 32, no. 17, pp. 1299-1311, 2011.

[2] S. Ebnesajjad, Handbook of Biopolymers and Biodegradable Plastics: Properties, Processing and Applications, Elsevier, 2012.

[3] G. E. Luckachan and C. K. S. Pillai, "Biodegradable polymers-a review on recent trends and emerging perspectives," Journal of Polymers and the Environment, vol. 19, no. 3, pp. 637-676, 2011.

[4] M. K. M. Haafiz, A. Hassan, Z. Zakaria, I. M. Inuwa, M. S. Islam, and M. Jawaid, "Properties of polylactic acid composites reinforced with oil palm biomass microcrystalline cellulose," Carbohydrate Polymers, vol. 98, no. 1, pp. 139-145, 2013.

[5] M. P. Arrieta, J. López, S. Ferrándiz, and M. A. Peltzer, "Characterization of PLA-limonene blends for food packaging applications," Polymer Testing, vol. 32, no. 4, pp. 760-768, 2013.

[6] E. Luiz De Paula, V. Mano, and F. V. Pereira, "Influence of cellulose nanowhiskers on the hydrolytic degradation behavior of poly(d,l-lactide)," Polymer Degradation and Stability, vol. 96, no. 9, pp. 1631-1638, 2011.

[7] D. Bondeson and K. Oksman, "Dispersion and characteristics of surfactant modified cellulose whiskers nanocomposites," Composite Interfaces, vol. 14, no. 7-9, pp. 617-630, 2007.

[8] R. Lipsa, N. Tudorachi, C. Vasile, A. Chiriac, and A. Grigoras, "Novel environmentally friendly copolymers carboxymethyl starch grafted poly(lactic acid)," Journal of Polymers and the Environment, vol. 21, no. 2, pp. 461-471, 2013.

[9] D. Shumigin, E. Tarasova, A. Krumme, and P. Meier, "Rheological and mechanical properties of poly(lactic) acid/cellulose and LDPE/cellulose composites," Medziagotyra, vol. 17, no. 1, pp. 3237, 2011.

[10] R. A. Auras, L.-T. Lim, S. E. Selke, and H. Tsuji, Poly(Lactic Acid): Synthesis, Structures, Properties, Processing, and Applications, Wiley, 2011.

[11] S. W. Hwang, J. K. Shim, S. Selke, H. Soto-Valdez, M. Rubino, and R. Auras, "Effect of maleic-anhydride grafting on the physical and mechanical properties of poly(L-lactic acid)/starch blends," Macromolecular Materials and Engineering, vol. 298, no. 6, pp. 624-633, 2013.

[12] M. M. F. Ferrarezi, M. de Oliveira Taipina, L. C. E. da Silva, and M. D. C. Gonçalves, "Poly(ethylene glycol) as a compatibilizer for poly(lactic acid)/thermoplastic starch blends," Journal of Polymers and the Environment, vol. 21, no. 1, pp. 151-159, 2013.

[13] T. Wang and L. T. Drzal, "Cellulose-nanofiber-reinforced poly (lactic acid) composites prepared by a water-based approach,"
ACS Applied Materials and Interfaces, vol. 4, no. 10, pp. 50795085, 2012.

[14] K. S. Chun, S. Husseinsyah, and H. Osman, "Properties of coconut shell powder-filled polylactic acid ecocomposites: effect of maleic acid," Polymer Engineering and Science, vol. 53, no. 5, pp. 1109-1116, 2013.

[15] H. Ku, H. Wang, N. Pattarachaiyakoop, and M. Trada, "A review on the tensile properties of natural fiber reinforced polymer composites," Composites Part B: Engineering, vol. 42, no. 4, pp. 856-873, 2011.

[16] M.-P. Ho, H. Wang, J.-H. Lee et al., "Critical factors on manufacturing processes of natural fibre composites," Composites Part B: Engineering, vol. 43, no. 8, pp. 3549-3562, 2012.

[17] A. A. Mamun and A. K. Bledzki, "Micro fibre reinforced PLA and PP composites: enzyme modification, mechanical and thermal properties," Composites Science and Technology, vol. 78, pp. 10-17, 2013.

[18] P. J. Jandas, S. Mohanty, and S. K. Nayak, "Surface treated banana fiber reinforced poly (lactic acid) nanocomposites for disposable applications," Journal of Cleaner Production, vol. 52, pp. 392-401, 2013.

[19] E. E. M. Ahmad and A. S. Luyt, "Morphology, thermal, and dynamic mechanical properties of poly(lactic acid)/sisal whisker nanocomposites," Polymer Composites, vol. 33, no. 6, pp. 1025-1032, 2012.

[20] F. J. Moscoso-Sánchez, O. J. R. Díaz, J. Flores et al., "Effect of the cellulose of Agave tequilana Weber onto the mechanical properties of foamed and unfoamed polypropylene composites," Polymer Bulletin, vol. 70, no. 3, pp. 837-847, 2013.

[21] P. J. Herrera-Franco and A. Valadez-González, "Mechanical properties of continuous natural fibre-reinforced polymer composites," Composites Part A: Applied Science and Manufacturing, vol. 35, no. 3, pp. 339-345, 2004.

[22] B. Imre and B. Pukánszky, "Compatibilization in bio-based and biodegradable polymer blends," European Polymer Journal, vol. 49, no. 6, pp. 1215-1233, 2013.

[23] H.-Z. Song, Z.-Q. Luo, C.-Z. Wang, X.-F. Hao, and J.-G. Gao, "Preparation and characterization of bionanocomposite fiber based on cellulose and nano- $\mathrm{SiO}_{2}$ using ionic liquid," Carbohydrate Polymers, vol. 98, no. 1, pp. 161-167, 2013.

[24] C. Miao and W. Y. Hamad, "Cellulose reinforced polymer composites and nanocomposites: a critical review," Cellulose, vol. 20, no. 5, pp. 2221-2262, 2013.

[25] A. Kumar, K. Karthick, and K. Arumugam, "Properties of biodegradable polymers and degradation for sustainable development," International Journal of Chemical Engineering and Applications, vol. 3, no. 2, pp. 164-167, 2011.

[26] A. N. Frone, S. Berlioz, J.-F. Chailan, D. M. Panaitescu, and D. Donescu, "Cellulose fiber-reinforced polylactic acid," Polymer Composites, vol. 32, no. 6, pp. 976-985, 2011.

[27] M. M. Kabir, H. Wang, K. T. Lau, and F. Cardona, "Chemical treatments on plant-based natural fibre reinforced polymer composites: an overview," Composites Part B: Engineering, vol. 43, no. 7, pp. 2883-2892, 2012.

[28] B. L. Peng, N. Dhar, H. L. Liu, and K. C. Tam, "Chemistry and applications of nanocrystalline cellulose and its derivatives: a nanotechnology perspective," The Canadian Journal of Chemical Engineering, vol. 89, no. 5, pp. 1191-1206, 2011.

[29] S. Kalia, B. S. Kaith, and I. Kaur, "Pretreatments of natural fibers and their application as reinforcing material in polymer composites-a review," Polymer Engineering \& Science, vol. 49, no. 7, pp. 1253-1272, 2009. 
[30] S. Andrade, Efecto de las condiciones de proceso de obtención de celulosa sobre sus propiedades fisicoquímicas [Tesis de Licenciatura], UADY, Mérida, México, 1998.

[31] J. Z. Lu, Q. Wu, and H. S. McNabb Jr., "Chemical coupling in wood fiber and polymer composites: a review of coupling agents and treatments," Wood and Fiber Science, vol. 32, no. 1, pp. 88104, 2000.

[32] S. W. Hwang, S. B. Lee, C. K. Lee et al., "Grafting of maleic anhydride on poly(L-lactic acid). Effects on physical and mechanical properties," Polymer Testing, vol. 31, no. 2, pp. 333-344, 2012.

[33] D. Plackett, "Maleated polylactide as an interfacial compatibilizer in biocomposites," Journal of Polymers and the Environment, vol. 12, no. 3, pp. 131-138, 2004.

[34] W. Z. Ouyang, Y. Huang, H. J. Luo, and D. S. Wang, "Preparation and properties of poly(lactic acid)/cellulolytic enzyme lignin/PGMA ternary blends," Chinese Chemical Letters, vol. 23, no. 3, pp. 351-354, 2012.

[35] H.-S. Yang, M. P. Wolcott, H.-S. Kim, S. Kim, and H.-J. Kim, "Effect of different compatibilizing agents on the mechanical properties of lignocellulosic material filled polyethylene biocomposites," Composite Structures, vol. 79, no. 3, pp. 369-375, 2007.

[36] S. Mazumdar, Composites Manufacturing: Materials, Product, and Process Engineering, CRC Press, Boca Raton, Fla, USA, 2001.

[37] L. Tong, A. P. Mouritz, and M. Bannister, 3D Fibre Reinforced Polymer Composites, Elsevier, 2002.

[38] M. N. Casaurang-Martinez, S. R. Peraza-Sanchez, and C. A. Cruz-Ramos, "Dissolving-grade pulps from Henequén fibers," Cellulose Chemistry and Technology, vol. 24, article 10, 1990.

[39] R. Zhu, Preparation of maleic anhydride grafted poly (lactid acid)(PLA) [M.S. thesis], Deparment of Mechanical and Materials Engineering, Washington State University, 2011.

[40] D. Carlson, L. Nie, R. Narayan, and P. Dubois, "Maleation of polylactide (PLA) by reactive extrusion," Journal of Applied Polymer Science, vol. 72, no. 4, pp. 477-485, 1999.

[41] S. Inkinen, M. Hakkarainen, A.-C. Albertsson, and A. Södergård, "From lactic acid to poly(lactic acid) (PLA): characterization and analysis of PLA and its precursors," Biomacromolecules, vol. 12, no. 3, pp. 523-532, 2011.

[42] S. Detyothin, S. E. M. Selke, R. Narayan, M. Rubino, and R. Auras, "Reactive functionalization of poly(lactic acid), PLA: effects of the reactive modifier, initiator and processing conditions on the final grafted maleic anhydride content and molecular weight of PLA," Polymer Degradation and Stability, vol. 98, no. 12, pp. 2697-2708, 2013.

[43] D. C. Montgomery, Design and Analysis of Experiments, John Wiley \& Sons, 8th edition, 2012.

[44] M. Avella, G. Bogoeva-Gaceva, A. Bužarovska, M. E. Errico, G. Gentile, and A. Grozdanov, "Poly(lactic acid)-based biocomposites reinforced with kenaf fibers," Journal of Applied Polymer Science, vol. 108, no. 6, pp. 3542-3551, 2008.

[45] Á. Csikós, G. Faludi, A. Domján, K. Renner, J. Móczó, and B. Pukánszky, "Modification of interfacial adhesion with a functionalized polymer in PLA/wood composites," European Polymer Journal, vol. 68, pp. 592-600, 2015.

[46] B. Pukánszky, "Influence of interface interaction on the ultimate tensile properties of polymer composites," Composites, vol. 21, no. 3, pp. 255-262, 1990.
[47] J. A. Nairn, Y. C. Liu, and C. Galiotis, Analysis of Stress Transfer from the Matrix to the Fiber through an Imperfect Interface: Application to Raman Data and the Single-Fiber Fragmentation Test, American Society for Testing and Materials, 1996. 

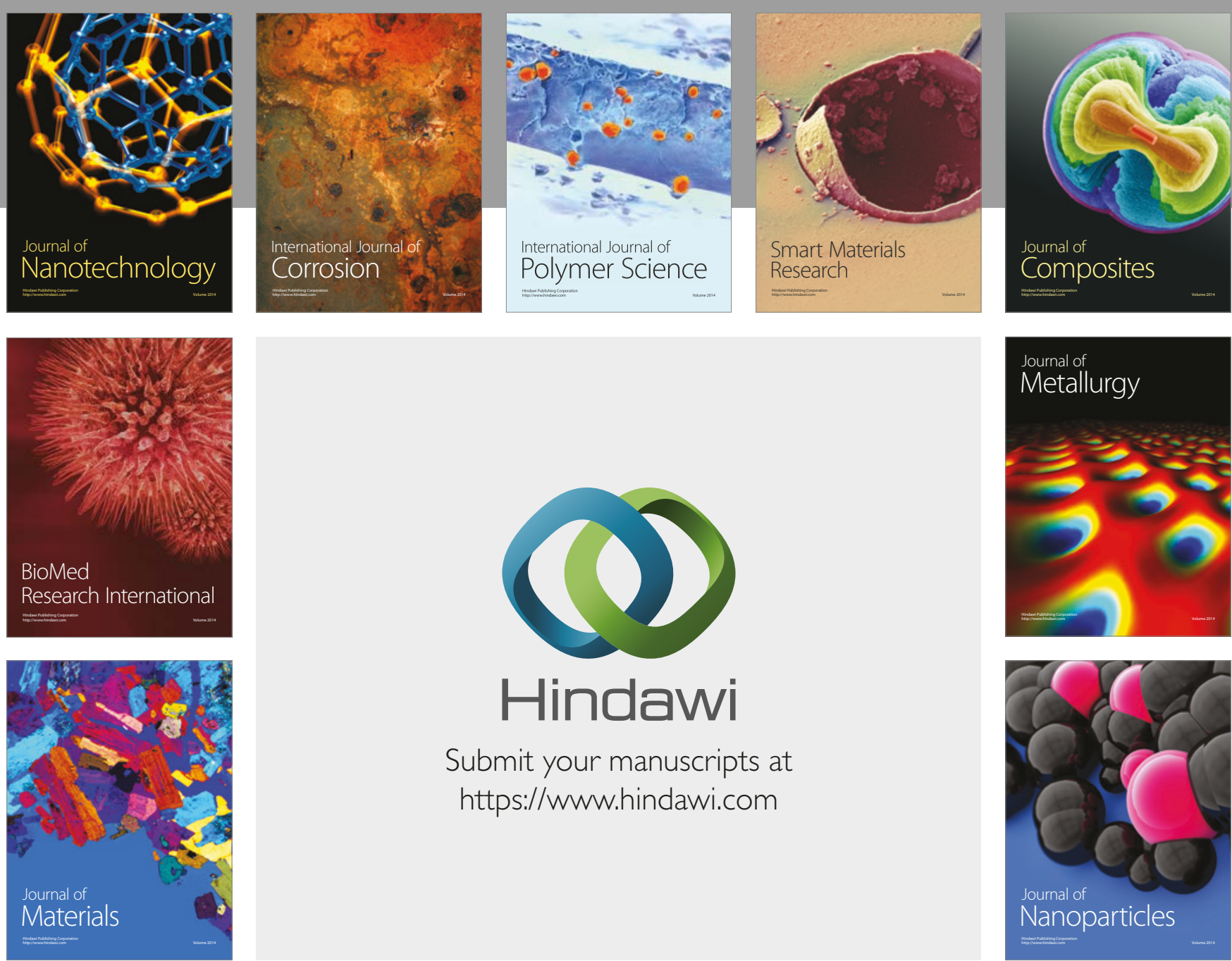

\section{Hindawi}

Submit your manuscripts at

https://www.hindawi.com
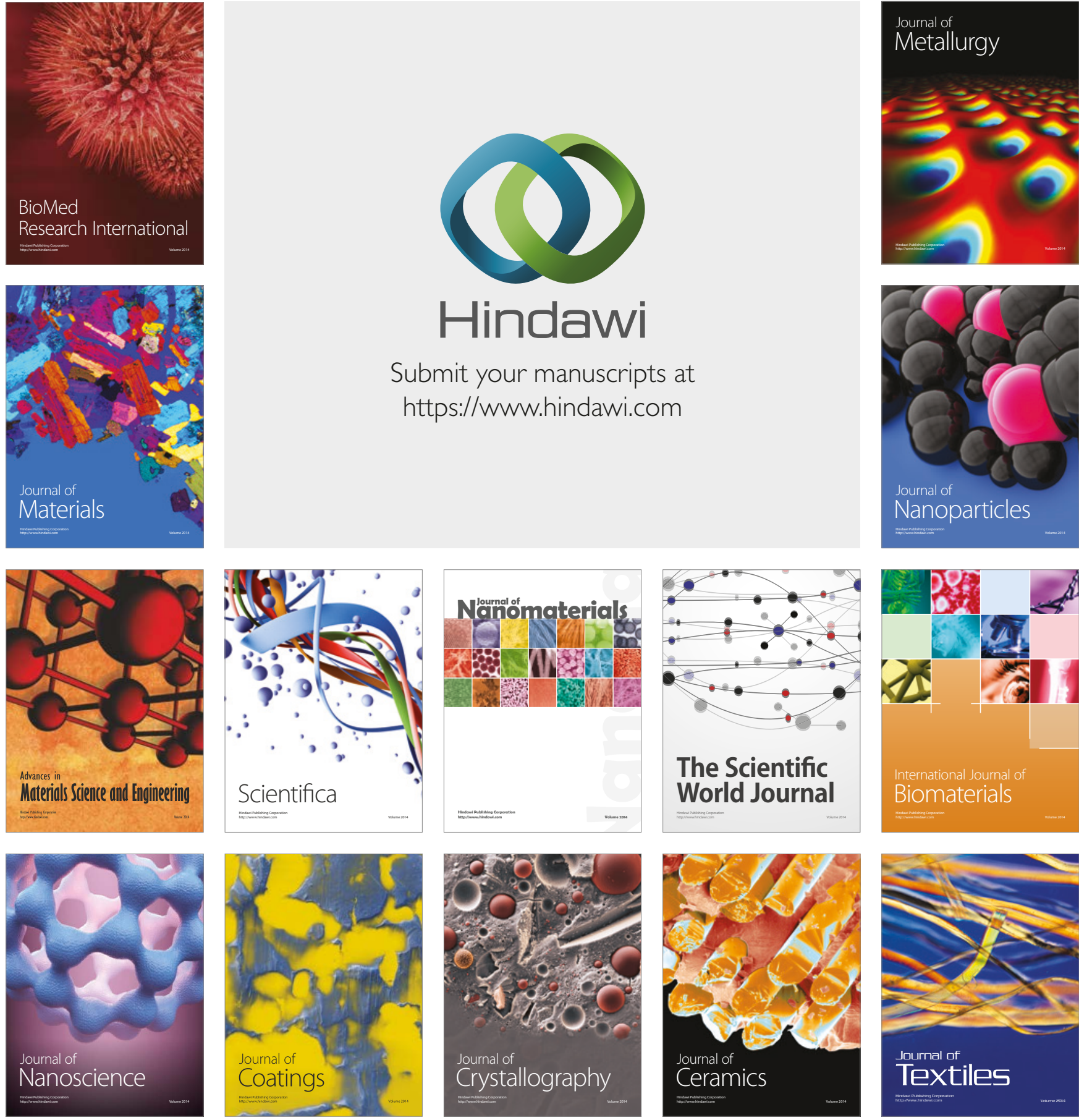

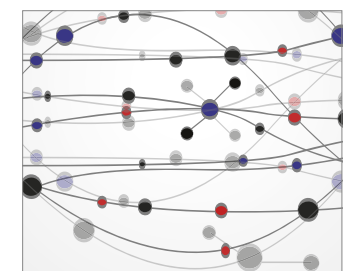

The Scientific World Journal
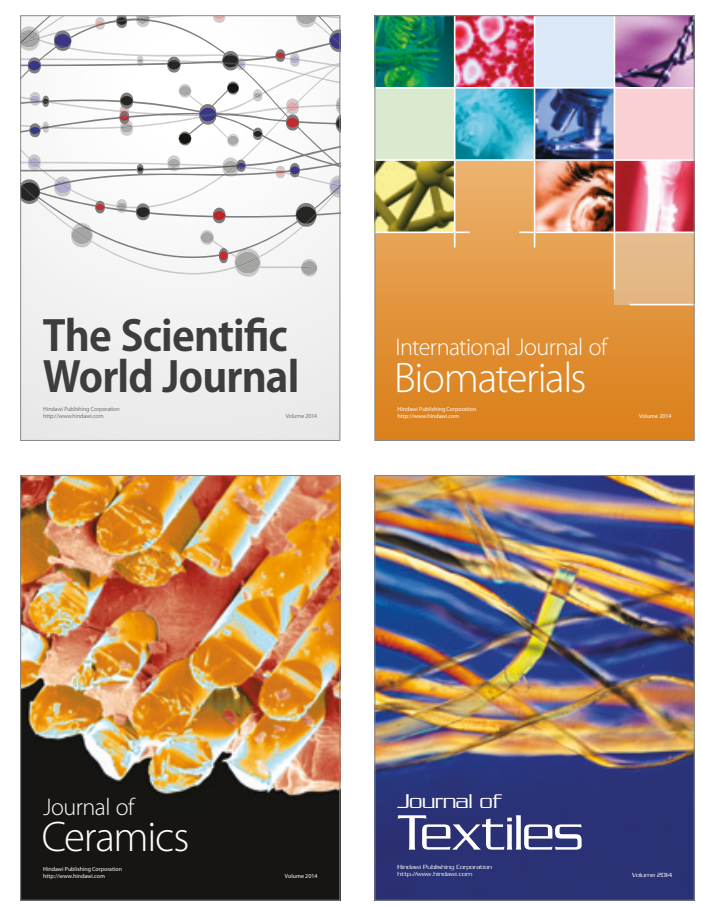